\title{
ANALISIS INDIKATOR UTAMA PENGELOLAAN HUTAN MANGROVE BERBASIS MASYARAKAT DI DESA CURAHSAWO KECAMATAN GENDING KABUPATEN PROBOLINGGO
}

\author{
Nuddin Harahab ${ }^{1}$ dan Graziano Raymond $\mathrm{P}^{2}$ \\ ${ }^{1}$ Fakultas Perikanan dan Ilmu Kelautan, Universitas Brawijaya \\ Jl. Veteran Malang - Indonesia \\ Telp. (0341) 553512/Fax.(0341) 557837 Email: marmunnuddin@yahoo.com \\ ${ }^{2}$ Direktorat Jendral KP3K, KKP \\ Diterima 23 Februari 2011 - Disetujui 21 Mei 2011
}

\begin{abstract}
ABSTRAK
Hutan mangrove merupakan salah satu sumber daya pesisir yang berperan penting dalam pembangunan ekonomi. Pengelolaan hutan mangrove berbasis masyarakat merupakan salah satu strategi pengelolaan yang dapat meningkatkan efisiensi dan keadilan dalam pemanfaatan dan pengelolaan sumber daya alam. Indikator penting dalam keberhasilan pengelolaan hutan mangrove adalah partisipasi masyarakat. Ada banyak variabel yang diperkirakan saling berinteraksi dan berkorelasi dalam partisipasi masyarakat tersebut. Oleh karenanya penelitian ini dilakukan untuk menganalisis dan menentukan indikator utama dalam pengelolaan hutan mangrove berbasis masyarakat. Penelitian ini menggunakan metode analisis Principle Component Analysis (PCA). Hasil analisis faktor menggunakan SPSS menunjukkan bahwa dari 15 (limabelas) variabel yang dianalisis diperoleh tiga indikator utama partisipasi masyarakat dalam pengelolaan hutan mangrove di Kecamatan Gending, yaitu faktor manajemen, pengetahuan, dan sikap.
\end{abstract}

Kata Kunci: hutan mangrove, analisis komponen utama, partisipasi

\section{Abstract : Analysis of Main Indicator in the Community-Based Management of Mangrove Forestry in the Curahsawo Vilage Subdistrict Gading, Probolinggo Regency by: Nuddin Harahab and Graziano Raymond P}

Mangrove forest is among coastal resources that has essential role in economic development. Community - based mangrove forest management is a strategy to improve efficiency and fairness in the use and management of natural resources mangrove forest.Important indicators in successing mangrove forest management is a community participation. There are many variables which were expected to interact with each other and correlated in community participation. Then study was conducted to analyze and determine primary indicators in community-based management of mangrove forestry. Method Principle Component Analysis (PCA) was used in this study. Results from factor analysis of 15 variables using SPSS shows that 3 major indicators of public participation in the mangrove forest management in district Gending are factor, knowledge and attitude.

Keywords: mangrove forestry, principle component analysis, participation. 


\section{PENDAHULUAN}

Pertumbuhan industri tambak udang telah mengakibatkan konversi lahan hutan mangrove dalam jumlah area yang cukup besar. Konversi hutan mangrove telah mengakibatkan penurunan produktivitas perikanan tangkap maupun budidaya di air payau (Hadipurnomo.1995; Khalil. 1999; Ronnback, 2002). Dibutuhkan pemulihan kondisi lingkungan kondisi pesisir utamanya hutan mangrove melalui reboisasi dan pengelolaan ekosistem yang lebih baik. Keberhasilan pengelolaan ekosistem hutan mangrove ditentukan oleh keterlibatan masyarakat yang bermukim di daerah pantai sebagai mitra dalam mengelola sumber daya alam pantai khususnya hutan mangrove (Melana, $d k k, 2000$ ).

Pengelolaan sumber daya berbasis masyarakat merupakan salah satu strategi pengelolaan yang dapat meningkatkan efisiensi dan keadilan dalam pemanfaatan dan pengelolaan sumber daya alam. Komunitas lokal memiliki keterikatan yang kuat dengan daerahnya sehingga pengelolaan yang dilakukan akan diusahakan demi kebaikan daerahnya. Berangkat dari asumsi bahwa ekosistem mangrove tidak semata merupakan sebuah sistem ekologi, tetapi juga sistem sosial, maka pengembangan sumber daya dengan memperhatikan sistem ekologi-sosial menjadi sebuah pendekatan yang penting. Bila mereka berdaya maka aturan lokal bisa melengkapi kekuatan hukum formal dan dapat menjadi pengawas yang efektif. Pengelola perikanan lokal didukung pengetahuan lokal (traditional ecological knowledge) yang akan berperan sebagai pendorong tumbuhnya ekonomi pesisir.

Untuk meningkatkan partisipasi masyarakat dalam pengelolaan hutan mangrove diperlukan pengetahuan tentang nilai strategis keberadaan hutan mangrove yang bermanfaat bagi masyarakat. Berbagai hasil penelitian menyebutkan bahwa pengurangan area hutan mangrove akan mengakibatkan hilangnya sumber penghasilan penting masyarakat setempat dan berpotensi meningkatkan konflik sosial (Paul, 2006). Thomason (2006) menyatakan bahwa ekosistem hutan mangrove memiliki nilai yang sangat penting bagi kehidupan masyarakat di area hutan di Esmeraldas, Ekuador. Hutan mangrove memiliki nilai penting khususnya bagi kehidupan wanita. Adanya tambak udang melalui konversi hutan mangrove terbukti memberikan pengaruh negatif yang sangat kuat bagi kehidupan masyarakat setempat. Grasso (1998) dan Gunarto (2004) menjelaskan bahwa ekosistem hutan mangrove memberikan layanan ekologis yang bagus untuk pelestarian habitat dan suaka margasatwa di sekitarnya. Hutan mangrove tidak diragukan dapat memberikan produk dan jasa bagi masyarakat yang tinggal di sekitarnya. Barbier (2006) menyatakan bahwa konversi lahan hutan mangrove ke tambak udang, mengakibatkan hilangnya sumber penghasilan utama masyarakat pantai yang semula bertumpu pada alam hutan mangrove. Kondisi tersebut telah mengundang perhatian masyarakat dan pemerintah dalam mencegah terjadinya konversi lahan lebih lanjut.

Keberhasilan pengelolaan hutan mangrove ditunjukkan oleh meningkatnya kualitas dan kuantitas hutan, yaitu bertambahnya luasan hutan, indek keragaman dan kerapatan vegetasi hutan. Indikator penting keberhasilan tersebut adalah tingkat keterlibatan atau partisipasi masyarakat Ada banyak variabel yang diperkirakan saling berinteraksi dan berkorelasi dalam membentuk hubungan dalam partisipasi masyarakat. Diperlukan penelitian yang dapat memperkecil jumlah variabel tersebut agar pengelolaan lebih terfokus dan mudah dikelola.

Penelitian ini dilakukan dengan tujuan untuk mereduksi variabel dengan melakukan analisis penentuan indikator utama dalam pengelolaan hutan mangrove berbasis masyarakat. Pengetahuan ini dapat digunakan untuk menyusun strategi peningkatan partisipasi masyarakat dalam pengelolaan ekosistem hutan mangrove. 


\section{METODOLOGI}

\section{Lokasi dan Waktu Penelitian}

Penelitian dilakukan di wilayah pesisir Desa Curahsawo, Kecamatan Gending, Kabupaten Probolinggo Provinsi Jawa Timur, penelitian ini dilakukan pada Bulan Juli sampai dengan September 2009.

\section{Jenis dan Sumber Data}

Data primer diperoleh dari beberapa kegiatan observasi, wawancara terhadap responden. Data primer yang dimaksud adalah penggalian sejauh mana pengetahuan masyarakat tentang hutan mangrove, keterlibatannya dalam kegiatan pengelolaan dan kesadaran masyarakat untuk berpatisipasi dalam upaya pengelolaan hutan mangrove. Data primer dikumpulkan dengan cara wawancara terstruktur kepada responden dengan menggunakan kuesioner. Data sekunder diperoleh dari dokumendokumen pada berbagai instansi, antara lain: Dinas Kehutanan dan Perkebunan, Dinas Kelautan dan Perikanan, dan BPS (Badan Pusat Statistik) Kabupaten Probolinggo.

\section{Metode Pengumpulan Data}

Penentuan responden dilakukan dengan menggunakan teknik purposive (sengaja) kepada para pengguna jasa lingkungan, pembudidaya udang (petambak), kelompok peduli lingkungan (Bentar Indah) dan aparat desa setempat. Hasil observasi digunakan untuk menegaskan dan mendukung jawaban yang telah didapatkan dari responden. Variabel yang digunakan untuk mengetahui sejauh mana partisipasi masyarakat terhadap upaya pengelolaan ekosistem mangrove adalah :

$\mathrm{Q}_{1}=$ tingkat pendidikan masyarakat dalam pengelolaan hutan mangrove/society's education level in a mangrove forest's management

$\mathrm{Q}_{2}=$ manfaat hutan mangrove yang diperoleh bagi masyarakat/the benefit of mangrove forest for the social community.
$\mathrm{Q}_{3}=$ dukungan/fasilitas yang diberikan masyarakat dalam pengelolaan hutan mangrove/ support/facilities which given by society in a management of mangrove forest.

$\mathrm{Q}_{4}=$ masyarakat menjadi mitra dalam pengelolaan hutan mangrove daripada hanya sebagai penerima manfaat/the society become partner in a management of mangrove forest rather than just take the benefit from it.

$\mathrm{Q}_{5}=$ masyarakat ikut mengelola hutan mangrove daripada hanya sebagai pengguna hutan mangrove/the society participate to manage the mangrove forest rather than just as the mangrove forest's user.

$\mathrm{Q}_{6}=$ masyarakat berpartisipasi dalam pembuatan keputusan dalam pengelolaan hutan mangrove/the society participate in a decision making at mangrove forest's management.

$\mathrm{Q}_{7}=$ pengelolaan hutan mangrove harus melalui proses belajar/berevolusi/ management of mangrove forest must through lerning/evolution process.

$\mathrm{Q}_{8}=$ pengelolaan hutan mangrove dilakukan secara terpusat/ managemet of mangrove forest is done centraly.

$\mathrm{Q}_{\mathrm{g}}=$ manajemen (perencanaan, pelaksanaan, monitoring) dalam pengelolaan hutan mangrove dilakukan sepenuhnya oleh pemerintah/ management (planning, implementing, monitoring) in a mangrove forest's management is done completely by the government.

$\mathrm{Q}_{10}=$ secara institusional dan administratif masyarakat ikut berpartisipasi dalam pengelolaan hutan mangrove/ the society participate in mangrove forest's management institutionaly and administratively.

$\mathrm{Q}_{11}=$ pelanggaran dalam pengelolaan hutan mangrove ditegakkan melalui aturanaturan yang menghukum/violation in mangrove forest's management should get a proper punishment. 
$\mathrm{Q}_{12}=$ manajemen pengelolaan hutan mangrove dilakukan secara fleksibel/flexibility at mangrove forest's management.

$\mathrm{Q}_{13}=$ pengelolaan hutan mangrove harus memiliki tujuan yang ganda/beragam/ the mangrove forest's management must have double/multi purpose.

$\mathrm{Q}_{14}=$ perlunya regenerasi alam dalam pengelolaan hutan mangrove/need of nature regeneration in mangrove forest's management.

$\mathrm{Q}_{15}=$ posisi masyarakat sebagai manager/ pelaksana/pemroses dalam pengelolaan hutan mangrove/ position of society as a manager/executor/user in mangrove forest's management.

\section{Metode Analisa Data}

Untuk melihat faktor-faktor partisipasi masyarakat digunakan Analisis Statistik Multivariat berupa Analisis Faktor yang didasarkan pada Analisis Komponen Utama, Supranto (2004) menjelaskan bahwa langkah-langkah yang diperlukan di dalam analisis faktor adalah:

\section{Matriks Korelasi}

Proses analitis didasarkan pada suatu matriks korelasi antar-variabel. Pendalaman yang berharga dapat diperoleh dari suatu pengkajian pada matriks korelasi ini. Agar analisis faktor bisa menjadi tepat, variabel-variabel yang dikumpulkan harus berkorelasi. Kalau korelasi antar-variabel memang kecil (hubungan lemah) analisis faktor menjadi tidak tepat. Di dalam analisis faktor diharapkan bahwa variabel-variabel tersebut mempunyai korelasi tinggi antar variabel dan korelasi yang tinggi dengan faktor-faktor.

\section{Metode Analisis Faktor}

Berdasarkan Bartlett's Test of Sphericity dan Kaiser-Meyer-Olkin (KMO) statistik di atas ternyata analisis faktor memang tepat untuk menganalisis data di atas. Dalam penelitian ini kita menggunakan Principal Component Anaylisis (PCA). Didalam PCA the total variance di dalam data yang diperhatikan yaitu diagonal matriks korelasi, setiap elemennya sebesar 1 (satu) dan full variance dipergunakan untuk dasar pembentukan faktor, yaitu variabelvariabel baru sebagai pengganti variabelvariabel lama, yang jumlanya lebih sedikit dan tidak lagi berkorelasi satu sama lain, seperti variabel asli yang memang saling berkolerasi.

\section{Penentuan Banyaknya Faktor}

Pendekatan yang digunakan dalam menentukan banyaknya faktor adalah berdasarkan pada eigen values. Masing-masing faktor hanya faktor dengan eigen values lebih dari 1 (satu) yang akan dipertahankan, faktor lainnya yang eigen values-nya satu atau kurang dari satu tidak lagi dimasukkan di dalam model.

\section{Interpretasi Hasil Rotasi}

Interpretasi mengenai faktor bisa dipermudah dengan mengenali (mengidentifikasi) variabel yang mempunyai nilai loading yang besar pada faktor yang sama. Faktor tersebut kemudian bisa diinterpretasikan menurut variabel-variabel yang mempunyai faktor loading sebagai titik koordinat.

\section{HASIL DAN PEMBAHASAN}

\section{Analisis Faktor Partisipasi Masyarakat}

\section{(1) Matriks Korelasi}

Proses analisis didasarkan pada suatu matriks korelasi agar variabel pendalaman yang berguna bisa diperoleh dari penelitian matriks ini. Agar analisis faktor bisa tepat dipergunakan, maka variabel-variabel yang akan dianalisis harus berkorelasi. Apabila koefisien korelasi antar-variabel terlalu kecil, hubungan lemah, analisis faktor tidak tepat. Diharapkan menghasilkan korelasi antara variabel asli dengan sesama variabel lainnya, juga berkorelasi dengan faktor sebagai variabel baru yang disaring dari variabel-variabel asli (multikolinearitas). Banyaknya faktor lebih sedikit daripada banyaknya variabel. Pada lampiran, bagian correlation matrix, pertama 
menggambarkan tentang koefisien korelasi antar-variabel. Misalnya, antara $\mathrm{Q}_{1}$ dan $\mathrm{Q}_{2}$, koefisien korelasinya adalah sebesar 0,815 dan antara $\mathrm{Q}_{9}$ dan $\mathrm{Q}_{14}$ sebesar 0,098. kedua menggambarkan tentang signifikansi korelasi itu.

Tabel pada lampiran menunjukkan signifikansi korelasi antara $\mathrm{Q}_{1}$ dan $\mathrm{Q}_{2}$ adalah 0,000 . Artinya, kita bisa menyimpulkan bahwa antara $\mathrm{Q}_{1}$ dan $\mathrm{Q}_{2}$ ada korelasi, dengan tingkat kesalahan $0,000 \%$ atau tingkat keyakinan $100 \%$. Sedangkan, antara $Q_{3}$ dan $Q_{9}$ tingkat signifikansinya hanya sebesar 0,470 , sehingga signifikansinya tidak diterima. Korelasi antarvariabel yang sama $\left(Q_{1}\right.$ dan $\left.Q_{1}\right)$, yang nilainya 1,000 tidak perlu diperhatikan. Karena variabelvariabel tersebut dikorelasikan dengan 'dirinya sendiri', perlu diperhatikan adalah korelasi antar-variabel yang berbeda.

\section{(2) Uji Kaiser Meyer Olkin (KMO) dan Barlett's}

Kesimpulan tentang layak-tidaknya analisis faktor dilakukan, baru sah secara statistik dengan menggunakan uji Kaiser Meyer Olkin (KMO) Measure of Adequacy dan Berlett Test of Spericity.

Dari hasil analisis dalam penelitian indikator pengelolaan hutan mangrove di Desa Curahsawo, Kecamatan Gending,
Kabupaten Probolinggo diperoleh nilai KMO MSA (Kaiser Meyer Olkin Measure of Sampling Adequacy) sebesar 0,705 artinya lebih besar dari 0,5. Hasil tersebut dapat disimpulkan bahwa analisis faktor layak dilakukan(Santoso, 2005).

Berlett Test of Spericity menunjukkan apakah antar-variabel terjadi korelasi atau hubungan dengan variabel lain dalam model atau tidak sehingga matriks korelasi yang dihasilkan cocok atau tepat atau dapat digunakan untuk analisis faktor. Syarat yang harus dipenuhi dari nilai rasio ini adalah mempunyai tingkat signifikansi $\leq 0,05$ atau lebih kecil sama dengan 5\%.

Dari hasil analisis data didapat nilai chi-square adalah 492,843, yang untuk derajat kebebasan (degree of freedom, disingkat df) sebesar 105, memiliki signifikansi 0,000 . Dari hasil tersebut dapat disimpulkan bahwa terjadi korelasi atau hubungan yang signifikan antar-variabel dalam model, sehingga matriks korelasi yang dihasilkan dapat digunakan untuk analisis faktor.

\section{(3) Jumlah Faktor Baru}

Output Total Variance Explained SPSS yang mempunyai eigenvalue $\geq 1$ dapat dilihat pada Tabel 1.

Tabel 1. Analisis Faktor SPSS dalam Penentuan Indikator Pengelolaan Hutan Mangrove di di Desa Curahsawo, Kecamatan Gending, Kabupaten Probolinggo, 2009

Table 1. Factor Analysis SPSS for Determinating the Indicator Management of Mangrove Forestry in the Curahsawo Villages, District Gending, Probolinggo Regency, 2009

\begin{tabular}{cccc}
\hline \multirow{2}{*}{$\begin{array}{l}\text { No. Faktor Baru/ } \\
\text { Number of New Factor }\end{array}$} & \multicolumn{3}{c}{ Factor Analysis SPSS } \\
\cline { 2 - 4 } & $\begin{array}{c}\text { Nilai Eigen/ } \\
\text { Eigen Value }\end{array}$ & $\begin{array}{c}\text { \% Varians/ } \\
\text { \% Varians }\end{array}$ & $\begin{array}{c}\text { \% Varians Kumulatif/ } \\
\text { \% Cumulative Varians }\end{array}$ \\
\hline 1 & 6,946 & 46,309 & 46,309 \\
2 & 2,893 & 19,286 & 65,594 \\
3 & 1,377 & 9,178 & 74,772 \\
\hline
\end{tabular}

Sumber: Diolah dari hasil pengolahan data SPSS

Source : Proceed from SPSS output data processing 
Faktor 1 (satu), memberikan sumbangan varian sebesar 6,946 yaitu sebesar $(6,946 / 15) \times 100 \%=46,309 \%$, terhadap seluruh varian sebesar 15 . Faktor 2 (dua) menyumbang 2,893 yaitu sebesar $(2,893 / 15) \times 100 \%=19,286 \%$ dan faktor 3 (tiga) memberikan sumbangan varian sebesar 1,377 yaitu sebesar $(1,377 / 15) \times 100 \%=9,178 \%$. Jadi, 3 (tiga) faktor pertama F1, F2 dan F3 sudah menyumbang varian sebesar $46,309 \%$ $+19,286 \%+9,178 \%=74,772 \%$. Artinya F1, F2, dan F3 sudah dapat menyerap informasi faktor-faktor sebelumnya sebanyak hampir $75 \%$.

\section{(4) Variabel Faktor Baru}

Variabel-variabel dari tiga faktor baru yang terbentuk memiliki kriteria Rotated Component Matrix lebih besar dari 0,5 (Santoso, 2005). Output Rotated Component Matrix dari SPSS dapat dilihat pada Tabel 2.

Pengelolaan ekosistem hutan mangrove dengan melibatkan masyarakat merupakan suatu proses yang dinamis dan berkelanjutan yang menyatukan berbagai kepentingan pemerintah dan masyarakat, ilmu pengetahuan dan pengelolaan, dan kepentingan sektoral dan masyarakat umum. Pengelolaan berbasis masyarakat disini adalah bahwa penggunaan dari sumber daya yang utama yaitu masyarakat dan harus menjadi aktor pengelola sumber daya tersebut.

Suatu pembangunan berbasis masyarakat dapat terbentuk, jika ada suatu kelompok berkolaborasi. Hal ini dikarenakan mereka sadar tidak dapat mengerjakan suatu tugas sendiri-sendiri dan tidak dapat mencapai tujuan secara individual baik karena sifat dari tugas atau tujuan itu sendiri, maupun karena keterbatasan sumber-sumber. Kebersamaan dan kesamaan dalam perhatian dan kepedulian, biasanya membuat masyarakat bersatu. Jika kebersamaan itu melembaga, dan menimbulkan kesetiakawanan, rasa saling percaya, terciptanya aturan-aturan main, maka inilah dasar dari terbentuknya basis masyarakat. Strategi yang tepat perlu dilakukan untuk menangani isu-isu yang mempengaruhi lingkungan pesisir melalui partisipasi aktif dan bentuk nyata dari masyarakat pesisir itu sendiri. Adanya partisipasi dari masyarakat merupakan hal yang penting dalam upaya pengelolaan hutan mangrove berbasis masyarakat. Banyak program dan kegiatan pengelolaan yang kurang berhasil dikarenakan pelaksanaan program yang gagal melibatkan partisipasi masyarakat sejak awal program.

Pada Tabel 2, hasil analisis faktor menggunakan SPSS menunjukan bahwa dari 15 variabel yang dianalisis diperoleh tiga faktor partisipasi masyarakat dalam pengelolaan hutan mangrove di Kecamatan Gending, yaitu faktor manajemen, pengetahuan, dan sikap:

Tabel 2. Komponen Matriks Berotasi (a) dalam Penentuan Indikator Pengelolaan Hutan Mangrove di Desa Curahsawo, Kecamatan Gending,Kabupaten Probolinggo, 2009

Table 2. Rotated Component Matrix (a) for Determinating the Indicator Management of Mangrove Forestry in the Curahsawo Villages, District Gending, Probolinggo Regency, 2009

\begin{tabular}{lccc}
\hline Variabel/ & \multicolumn{3}{c}{ Komponen/Component } \\
\cline { 2 - 4 } Variable & $\mathbf{1}$ & $\mathbf{2}$ & $\mathbf{3}$ \\
\hline $\mathrm{Q}_{1}$ & & 0.928 & \\
$\mathrm{Q}_{2}$ & & 0.852 & \\
$\mathrm{Q}_{3}$ & & 0.895 & \\
$\mathrm{Q}_{4}$ & 0.847 & & \\
$\mathrm{Q}_{5}$ & 0.876 & & \\
$\mathrm{Q}_{6}$ & 0.800 & & \\
$\mathrm{Q}_{7}$ & 0.678 & & \\
$\mathrm{Q}_{8}$ & & 0.894 & \\
$\mathrm{Q}_{9}$ & 0.768 & & \\
$\mathrm{Q}_{10}$ & 0.867 & & 0.745 \\
$\mathrm{Q}_{11}$ & & & \\
$\mathrm{Q}_{12}$ & 0.664 & & \\
$\mathrm{Q}_{13}$ & 0.747 & & \\
$\mathrm{Q}_{14}$ & & & \\
$\mathrm{Q}_{15}$ & 0.5926 & &
\end{tabular}




\section{a. Faktor Manajemen}

Faktor manajemen terdiri dari sembilan variabel yang dapat dijabarkan sebagai berikut: (1) masyarakat menjadi mitra dalam pengelolaan hutan mangrove; (2) masyarakat ikut mengelola; (3) masyarakat berpartisipasi dalam pembuatan keputusan; (4) masyarakat berproses dalam pengelolaan; (5) perencanaan, pelaksanaan, monitoring dalam pengelolaan hutan mangrove dilakukan oleh pihak pemerintah; (6) partisipasi masyarakat secara institusional dan administratif; (7) manajemen pengelolaan dilakukan secara fleksibel; (8) pengelolaan hutan mangrove memiliki tujuan ganda; dan (9) masyarakat sebagai manajer/ pelaksana/ pemroses dalam pengelolaan hutan mangrove. Dari hasil interpretasi dapat menjelaskan 46,309\% dari keseragaman total, artinya keputusan partisipasi masyarakat dalam pengelolaan hutan mangrove $46,309 \%$ ditentukan oleh faktor manajemen.

\section{b. Faktor Pengetahuan}

Faktor pengetahuan terdiri dari empat variabel yang dapat dijabarkan sebagai berikut: (1) tingkat pendidikan masyarakat dalam pengelolaan hutan mangrove; (2) manfaat hutan mangrove yang diperoleh bagi masyarakat; (3) dukungan/ fasilitas yang diberikan masyarakat dalam pengelolaan hutan mangrove; dan (4) sistem dalam pengelolaan hutan mangrove. Dari hasil interpretasi dapat menjelaskan $19,286 \%$ dari keseragaman total, artinya keputusan partisipasi masyarakat dalam pengelolaan hutan mangrove 19,286\% ditentukan oleh faktor pengetahuan.

\section{c. Faktor Sikap}

Faktor sikap terdiri dari dua variabel yang dapat dijabarkan sebagai berikut: (1) pelanggaran yang terjadi dalam pengelolaan hutan mangrove; dan (2) regenerasi alam dalam pengelolaan hutan mangrove. Dari hasil interpretasi dapat menjelaskan 9,178\% dari keseragaman total, artinya keputusan partisipasi masyarakat dalam pengelolaan hutan mangrove $9,178 \%$ ditentukan oleh faktor sikap.

Analisis faktor dalam meringkas variabel yang banyak diubah menjadi sedikit variabel (faktor), maka dapat menjelaskan hubungan antar faktor dari banyak variabel yang saling terkait (berhubungan) diteliti dan dinyatakan dalam sedikit faktor. Dengan demikian sedikit faktor tersebut (manajemen, pengetahuan dan sikap) harus dikelola dengan baik untuk meningkatkan partisipasi masyarakat dalam pengelolaan ekosistem hutan mangrove, karena pada dasarnya faktor tersebut masih mengandung atau memuat sebagian besar variabel asli.

\section{KESIMPULAN DAN IMPLIKASI KEBIJAKAN}

Indikator utama pengelolaan hutan mangrove berbasis masyarakat dari 15 (lima belas) variabel yang dianalisis diperoleh tiga faktor, yaitu faktor manajemen, pengetahuan, dan sikap. Sebagai indikator utama faktor manajemen memposisikan masyarakat sebagai mitra dan secara terus-menerus berproses dalam pelibatan partisipasi.

Implikasi kebijakan yang dapat diambil, bahwa peningkatan partisipasi masyarakat dalam pengelolaan hutan mangrove dapat dibangun melalui faktor manajemen, dengan menciptakan rasa memiliki. Disamping meningkatkan pengetahuan terhadap manfaat dan nilai hutan mangrove.

\section{DAFTAR PUSTAKA}

Barbier. E. B. 2006. 10 Mangroves Dependency and the Livelihoods of Coastal Communities in Thailand. Environment and Livelihoods in Tripical Coastal Zones (Eds. C.T. Hoanh, T.P.Tuong, J.W, Growing and B.Hardy). $126-139 p p$. 
Grasso, M. 1998. Ecological-Economic Model for Optimal Mangrove Trade off Between Forestry and Fishery Production: Comparing a dynamic optimization and a simulation model. Elsevier, Ecological Modeling. 131-150pp.

Gunarto, 2004. Konservasi Mangrove Sebagai Pendukung Sumber Hayati Perikanan Pantai. Jurnal Litbang Pertanian, 23 (1).

Hadipurnomo. 1995. Fungsi dan Manfaat Mangrove di Dalam Mintakat Pantai (coastal Zone), Duta Rimba/ Maret - April /177-178/XXI/1995. Hal 11.

Khalil, S. 1999. The Economic Value of The Environment : Cases from South Asia. IUNC. www.iucnus.org/publication.html. Diakses tanggal 27 September 2007.

Melana, D. M., Emma, E. Melana, M.F and A. M. Mapalo. 2000. Mangrove Managemen and Development In Philippines. Presented during the meeting on "Mangrove and Aquaculture Management" helt at Kasetsart Univ.Campus, Bangkok, Thailand on February 14-16. 1 -11pp.
Paul, U.S. 2006. 12 Interelation Among Mangroves, the Local and Social Sustainability: a Review from a Case Study in North Brazil. Environment and Livelihoods in Tripical Coastal Zones (Eds. C.T. Hoanh, T.P.Tuong, J.W, Growing and B.Hardy). $154-161 p p$.

Ronnback, P. 2002. Environmentally Sustainable Shrimp Aquaculture. Prepared for Swedish Society for Nature Conservation. 1-21pp.

Santoso, S. 2005. Statistik Multivatiat. Panduan langkah-demi langkah dilengkapi studi kasus. P.T. Elex Media Komputindo, Kelompok Gramedia, Jakarta. Hal 45.

Supranto. 2004. Analisis Multivariat: Arti dan Interpretasi. P.T. Rineka Cipta. Jakarta. Hal 24.

Thomason, P. O. 2006. 11 Mangroves, People and Cockles: Impacts of the Shrim-Farming Industri on Mangrove Communities in Esmeraldas Propince, Ecuador. Environment and Livelihoods in Tripical Coastal Zones (Eds. C.T. Hoanh, T.P. Tuong, J.W, Growing and B.Hardy). $140-153 p p$. 


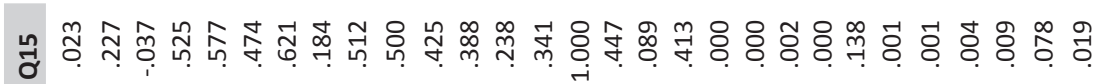

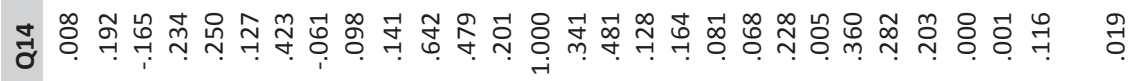

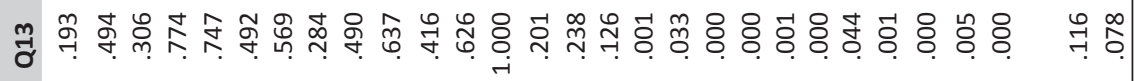

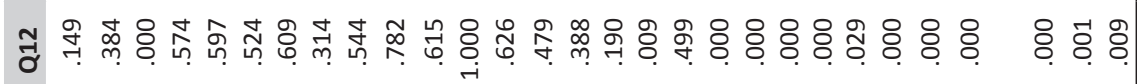

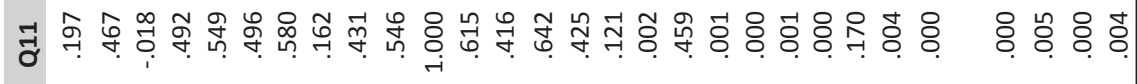

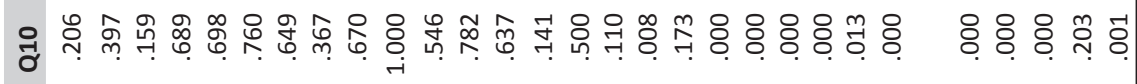

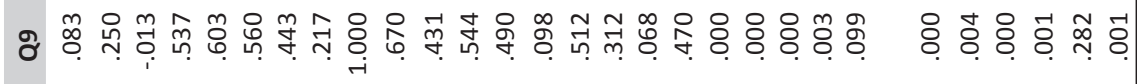

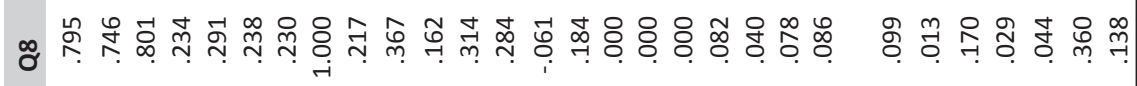

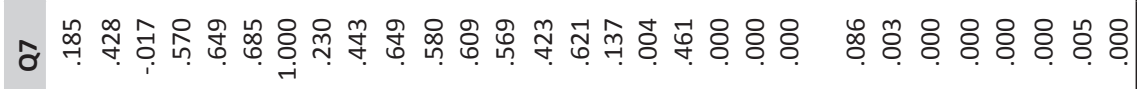

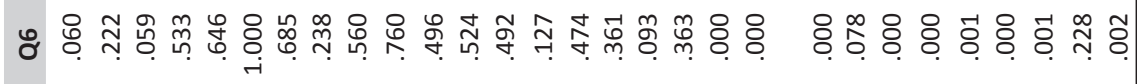

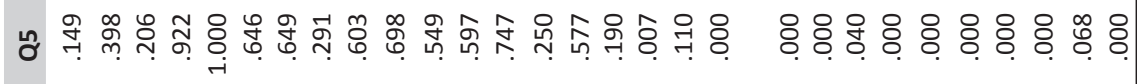
ব

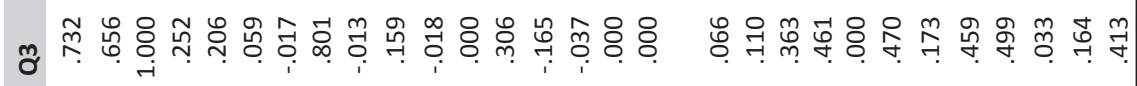

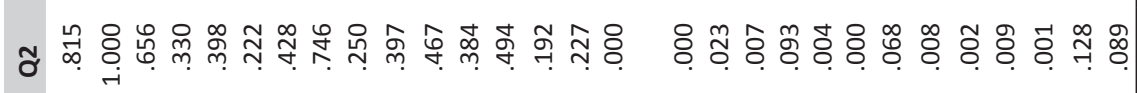

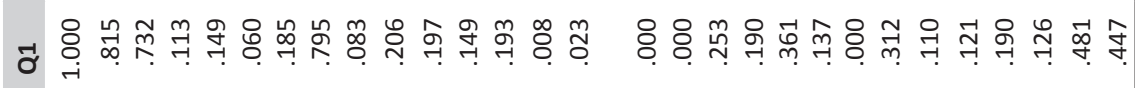

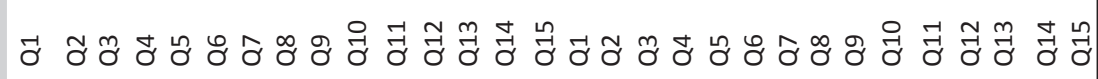
㐫 